This item was submitted to Loughborough's Research Repository by the author.

Items in Figshare are protected by copyright, with all rights reserved, unless otherwise indicated.

\title{
Decomposing energy demand across BRIIC countries
}

\section{PLEASE CITE THE PUBLISHED VERSION}

http://dx.doi.org/10.1016/j.eneco.2016.01.001

\section{PUBLISHER}

(c) Elsevier

\section{VERSION}

AM (Accepted Manuscript)

\section{PUBLISHER STATEMENT}

This work is made available according to the conditions of the Creative Commons Attribution-NonCommercialNoDerivatives 4.0 International (CC BY-NC-ND 4.0) licence. Full details of this licence are available at: https://creativecommons.org/licenses/by-nc-nd/4.0/

\section{LICENCE}

CC BY-NC-ND 4.0

\section{REPOSITORY RECORD}

Adetutu, Morakinyo O., Anthony J. Glass, and Thomas G. Weyman-Jones. 2019. "Decomposing Energy Demand Across BRIIC Countries". figshare. https://hdl.handle.net/2134/20135. 


\title{
Decomposing energy demand across BRIIC countries
}

\author{
Morakinyo O. Adetutu*, Anthony J. Glass, Thomas G. Weyman-Jones \\ Department of Economics, Loughborough University, \\ United Kingdom
}

January 2016

*Corresponding author: Email: M.O.Adetutu@lboro.ac.uk , Tel: +44 -1509-222704. 


\begin{abstract}
Energy plays an important role within the production technology of fast emerging economies, such that firms' reaction to changes in energy prices provides useful information on factor productivity and factor intensity, as well as the likely outcome of energy policy initiatives, among other things. Drawing on duality theory, this paper decomposes changes in energy demand into substitution and output effects using annual sector-level production data for Brazil, Russia, India, Indonesia and China (BRIIC) for the period 1995-2009. Unlike previous studies, this study analyzed the economic properties of the underlying production technology. Results indicate that changes in energy demand are strongly dominated by substitution effects. More importantly, an intriguing finding that emerges from our analysis is the role of economies of scale and factor accumulation, as opposed to technical progress, in giving rise to the growth performance of sampled economies.
\end{abstract}

Keywords: BRIIC Countries, Input Demand, Duality, Production Technology, Translog Cost Function, Slutsky Decomposition.

JEL Classification: C3, D22, O40, Q40 


\section{Introduction}

Energy plays an important role within the production technologies of fast emerging economies, given that a significant proportion of their energy consumption is embedded in the creation of goods and services. Never before has it been so important to understand the contributions of energy demand in fast emerging economies, considering that their economic growth and development increasingly burden the global environment as they lift millions of people from poverty (see Goel and Korhonen, 2012). The extant literature abounds with empirical econometric studies aimed at estimating industrial energy demand (e.g. Medlock III and Soligo, 2001; Dimitropoulos et al., 2005; Adeyemi and Hunt, 2014).

Typically, these studies provide estimates of price and income elasticity by estimating single equation models of energy demand as a function of energy price, output and other control variables such as temperature. These exiting studies suffer from three major flaws. First, there is an implicit assumption that other factor inputs within the production technology are held constant since the demand for energy is estimated separately from the demand for other factor inputs in a single equation context ${ }^{1}$. These short-run models would imply that the demand for energy is independent of the demand for other factor inputs, thereby precluding economic theory's prescription of factor substitution in the face of changing relative input prices.

Second, the functional specification of the estimated models provides no information on the structure and nature of the production technology, since most of the models simply specify restrictive demand functions with energy price and output as independent variables. For instance, economic intuition suggests that relative factor intensity depends on the substitution possibilities

\footnotetext{
${ }^{1}$ One could argue that such studies have estimated short-run input demand functions by holding other factor inputs constant.
} 
between factor inputs and the nature of technical progress within the technology. Third, existing studies tend to use aggregate industrial data in their estimations, thereby masking the differences in the production processes across the various productive sectors in an economy.

Another strand of the energy demand literature addresses the first issue (of factor independence) above by specifying multi-input production functions, following the seminal work of Berndt and Wood (1975, 1979). These studies tend to focus on estimating substitution elasticity and inter-fuel substitution (e.g, Hunt, 1984, 1986; Roy et al., 2006; Koetse et al., 2008; Broadstock, 2010) ${ }^{2}$. While substitution possibilities (depicted by movements along an isoquant) between energy and other factor inputs provide useful information on the likely impact of changing relative prices or changing energy policies, these substitution elasticity studies generally ignore output effects ${ }^{3}$. As shown by Chambers (1982), the output effect presents a more complete picture of input adjustments within a production technology than do substitution elasticities, since such elasticities implicitly assume a constant level of output or restrict the producer to a given level of output. However, in reality producers constantly adjust output in response to changes in relative factor prices and other market conditions.

Moreover, as stated in the second limitation above, previous substitution elasticity studies also fail to account for the nature of the underlying production function, especially as relating to the economic properties/regularity conditions of the underlying production function. For instance, microeconomic theory suggests that a well-behaved production technology should exhibit monotonicity and curvature properties, which are required to arrive at robust and

\footnotetext{
${ }^{2}$ Other studies such as Thompson (2006) and Stern (2011) provide theoretical exposition on the concept of substitution elasticities.

${ }^{3}$ Output effects reflect the changing output decisions arising from shifts in the isocost facing the firm.
} 
theoretically tenable set of results ${ }^{4}$. In line with this argument, to generate credible results from a cost function, for instance, it is required that the cost function is monotonic (non-decreasing in input prices and output), concave and continuous in inputs prices. Unless these regularity conditions are assessed, it is impossible to know if previously estimated substitution elasticties are consistent with standard regularity conditions.

Drawing on duality theory, this paper decomposes changes in energy demand into substitution and output effects using sector-level production data for Brazil, Russia, India, Indonesia and China (BRIIC). In addition, we assessed the economic properties (monotonicity, concavity and technical progress) $)^{5}$ of the estimated cost function. Our aim is to gain as much useful insight about the production technology as possible while analyzing the role of energy demand. For instance, technical change yields productivity information on whether a production technology was shifting up or down over time. More specifically we re-visit the typical assumption of Hick-neutral technical change in the presence of biased technical progress which could be misleading and may result in biased parameter estimates (Kim, 1987). The Hicksneutral assumption of constant and identical rate of technical progress for each factor input can be overly restrictive given the wide-ranging innovative (R\&D) activities of firms. Hence, we tested for biased technical change which allowed us to determine if technical change was energyusing or energy-saving during the period under consideration. Our approach therefore allows for the treatment of these issues without making the overly restrictive assumptions in other studies.

\footnotetext{
${ }^{4}$ Further, as shown in this study, microeconomic concepts such as economies of scale and technical progress contain valuable information that are useful for understanding the nature and structure of a production technology.

${ }^{5}$ For instance see Saunders $(2008,2013)$ for a discussion on the need to ensure concavity of the cost function. See appendix 2 for details of economic tests undertaken.
} 
Figure 1: Industrial Share of Total Energy Consumption (\%)

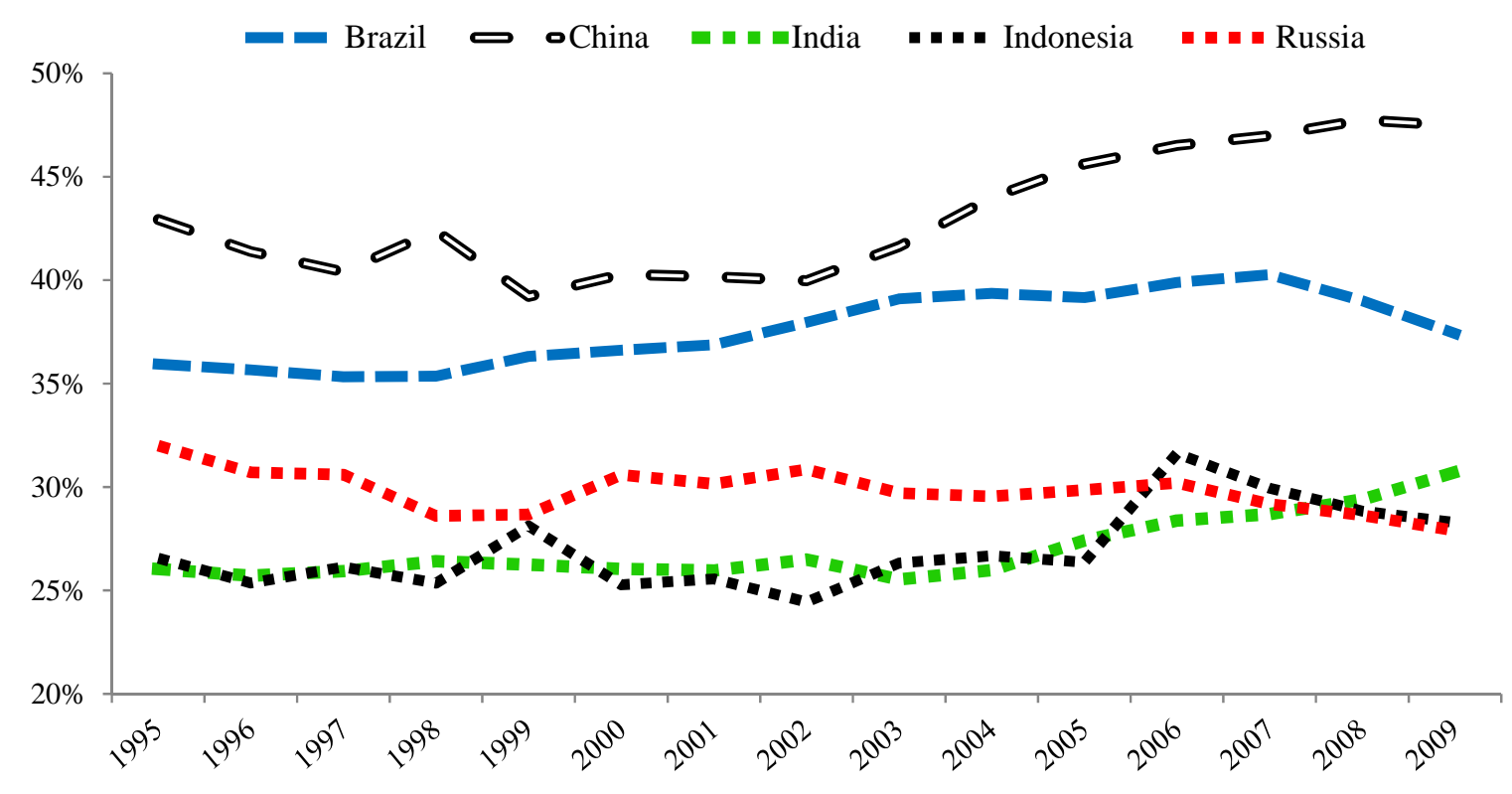

Source: IAE, 2014

Our estimations are based on sector-level production data for Brazil, Russia, India, Indonesia and China (BRIIC) covering the period 1995-2009. Our choice of sampled countries hinges on a number of crucial considerations. First, these countries are important (dominant) high-population and high-growth emerging economies that increasingly burden the global environment as they lift millions of people from poverty. Second, they have large manufacturing and energy/emissions-intensive sectors compared with other major and emerging economies. Figure 1 illustrates that their industrial energy share of total energy demand is consistently greater than $25 \%$ and is generally rising. Finally, analyzing industrial energy consumption in these economies is vitally important given that a great deal of energy use is "embedded energy" contained in the creation of goods and services (Costanza, 1980). 
The remainder of this paper proceeds as follows. Section 2 presents the empirical methodology used in this paper. The data set is described in section 3, focusing on how the input prices and cost data are computed. Section 4 presents the empirical results of this paper and is divided into 3 subsections, comprising the discussion of the estimates of the estimated cost function, substitution elasticities estimates and the decomposition of energy demand. We conclude in Section 5 by using the estimation results to provide key insight on energy demand across sampled economies.

\section{Empirical Framework}

In our analysis, we identify four input types: capital, labour, energy and materials (the familiar KLEM), together with the input prices: $w_{K}, w_{L}, w_{E}, w_{M}$.

\subsection{Translog Cost Function}

We proceed by invoking the microeconomic assumption that firms minimize input costs $\left(w_{K} K+w_{L} L+w_{E} E+w_{M} M\right)$ subject to the production of a given level of output $(y)$ as determined by a standard production function $F(x)$ so that:

$$
\begin{gathered}
C\left(y, w_{K}, w_{L}, w_{E}, w_{M}\right)=\min _{K, L, E, M}\left(w_{K} K+w_{L} L+w_{E} E+w_{M} M\right) \\
\text { s.t. } \quad y=F(x)
\end{gathered}
$$

where:

$$
C \equiv \sum_{i} w_{k} x_{k} \text { and } x_{k} \text { is the typical input K,L,E,M }
$$

$$
y \text { : Output }
$$

$w_{K}$ : Price of Capital

$w_{L}$ : Price of Labour 


\author{
$w_{E}$ : Price of Energy \\ $w_{M}$ : Price of Material \\ $K$ : Capital \\ L: Labour \\ $E$ : Energy \\ $M$ : Material
}

In the empirical economics literature, studies have relied on different functional forms such as the Cobb-Douglas, Leontief and the CES in estimating (1). However, these functions impose a-priori restrictions on the model in terms of scale economies and the substitution possibilities among the factor inputs. Consequently, we use the translog cost function (Christensen et al., 1973) due to its flexibility which allows for the calculation of second order effects and non-constant elasticities and shares, without placing a-priori restrictions on the production technology. The translog cost function for sector $i$ in period $t$ using $k$ inputs in this study can be written in the context of panel data as:

$$
\begin{aligned}
\ln C_{i t}= & \alpha_{0}+\alpha_{y} \ln y_{t}+\sum_{k=1}^{4} \beta_{k} \ln w_{k i t}+\frac{1}{2} \alpha_{y y} \ln y_{t}^{2}+\frac{1}{2} \sum_{k=1}^{4} \sum_{l=1}^{4} \gamma_{k l} \ln w_{k i t} \ln w_{l i t} \\
& +\sum_{k=1}^{4} \delta_{k} \ln w_{k i t} \ln y_{t}+\theta_{1} t+\theta_{2} t^{2}+\varphi_{t} \ln y_{t} t+\sum_{k=1}^{4} \xi_{k} \ln w_{k i t} t+v_{i t}
\end{aligned}
$$


where all variables remain as defined above and $\alpha_{y}, \beta_{k}, \alpha_{y y}, \gamma_{k l}, \delta_{k r}, \theta_{1}, \theta_{2}, \varphi_{t}, \xi_{t}$ are all parameters to be estimated. Duality theory requires that fundamental restrictions of symmetry and linear homogeneity in the input prices are imposed, so that:

$$
\begin{gathered}
\beta_{i j}=\beta_{j i}, \forall i j \\
\sum_{i} \beta_{i}=1 \\
\sum_{i} \delta_{k r}=0, \forall r \\
\sum_{j} \gamma_{k l}=0, \forall k l \\
\sum_{i} \xi_{t}=0
\end{gathered}
$$

Given the foregoing, the symmetry condition is imposed implicitly in the model specification, while homogeneity (condition ii above) is imposed by normalizing ${ }^{6}$ the input prices and total cost by $w_{m}$ so that the estimated cost function can be written as:

$$
\begin{aligned}
\ln \frac{C_{i t}}{w_{m}}= & \alpha_{0}+\alpha_{y} \ln y_{t}+\sum_{k=1}^{3} \beta_{k} \ln \frac{w_{k i t}}{w_{m}}+\frac{1}{2} \alpha_{y y} \ln y_{t}^{2}+\frac{1}{2} \sum_{k=1}^{3} \sum_{l=1}^{3} \gamma_{k l} \ln \frac{w_{k i t}}{w_{m}} \ln \frac{w_{l i t}}{w_{m}} \\
& +\sum_{k=1}^{3} \delta_{k} \ln \frac{w_{k i t}}{w_{m}} \ln y_{t}+\theta_{1} t+\theta_{2} t^{2}+\varphi_{t} \ln y_{t} t+\sum_{k=1}^{3} \xi_{k} \ln \frac{w_{k i t}}{w_{m}} t+v_{i t}
\end{aligned}
$$

\footnotetext{
${ }^{6}$ In this study, the normalizing input price is the material input price
} 
For a given level of output, the cost minimizing input demand functions can be derived via Shephard's lemma by differentiating (5) above with respect to each input price so that $S_{k i t}=$ $\frac{\partial \ln c_{i t}}{\partial \ln w_{k i t}}=x_{k i t} ; k=(K, L, E, M)$ and the input demand equations in terms of cost shares can therefore be obtained as:

$$
S_{k i t}=\beta_{k}+\sum_{l=1}^{3} \gamma_{k l} \ln \frac{w_{l i t}}{w_{k i t}}+\delta_{k} \ln y_{t}+\xi_{k} t
$$

where $S_{k}$ is the cost share ${ }^{7}$ of the $k$ th input. We jointly estimate equations 5 and $6^{8}$ using seemingly unrelated regression equations (SUR) by iterative/feasible GLS which is known to converge on the maximum likelihood estimation (MLE). The joint estimation of the share equations allows us to increase the degrees of freedom and efficiency of the parameter estimates by exploiting correlations between the errors of the share equations.

\subsection{Substitution Elasticities}

It is possible to compute substitution elasticities between energy and non-energy inputs from (5). For a cost function, the most common elasticity of substitution (ES) used in empirical studies is the Allen Elasticity of Substitution (AES) ${ }^{9}$. For the translog cost function, the ES can be written as:

$$
\sigma_{k l}^{A E S}=\frac{\gamma_{k l}+S_{k} S_{l}}{S_{k} S_{l}} ; \quad \sigma_{k k}^{A E S}=\frac{\gamma_{k k}+S_{k}^{2}-S_{k}}{S_{k}^{2}}
$$

\footnotetext{
${ }^{7}$ Given that we have 4 factor inputs, our model includes only three share equations as the sum of the shares is one, so that only three of the factor shares are independent, hence one share equation (for materials) is omitted.

${ }^{8}$ The Seemingly Unrelated Regression (SUR) System estimation is conducted using the Zellner's iterative method for SUR models by imposing the restrictions in (4) using STATA 12.

${ }^{9}$ This is also known as the Allen-Uzawa Elasticity of Substitution (Allen, 1938; Uzawa, 1962)
} 
where $S_{k}$ and $S_{l}$ are the factor shares of inputs $k$ and $l$ respectively. $\gamma_{k l}$ and $\gamma_{k k}$ are estimated coefficients from the cost function where $\gamma_{k l}$ is the cross-price coefficient between inputs $k$ and $l$, whereas $\gamma_{k k}$ is the second-order coefficient for input $k$.

Blackorby and Russell (1981) demonstrated that the AES is a limited measure of ES as it ignores information on relative factor shares. Consequently, they argued that the AES cannot be interpreted as an indicator of the curvature of a production technology. To this end, they proposed the Morishima (1967) elasticity of substitution (MES) as a more appropriate measure of the ES since it allows for the evaluation of the elasticity of change in input ratios with respect to price ratios for a given level of output, while allowing for input adjustments, holding prices constant (see Stern, 2011). Furthermore, unlike the AES, the MES is asymmetric in nature, hence $M E S_{k l} \neq M E S_{l k}$. Stern (2011) argues that a measure such as the MES which allows for optimal input changes is more appropriate for capturing changes in factor shares when all inputs are variable within a cost-minimizing production technology. The MES is given as:

$$
\sigma_{k l}^{M E S}=s_{l}\left(\gamma_{k l}-\gamma_{l l}\right)
$$

The MES measures the percentage change in the ratio $k / l$ due changes in the price of $l$ so that if $\sigma_{k l}^{M E S}>0$ then an increase in the price of $l$ stimulates an increase in the optimal use of input $k$ relative to the optimal use of $l$ (in other words, input $k$ substitutes for $l$ ). However, we conclude that there is complementarity between the two inputs when $\sigma_{k l}^{M E S}<0$. Because the MES is asymmetric in nature, confirming substitutability or complementarity depends on which input price changes ${ }^{10}$.

\footnotetext{
${ }^{10}$ We adopt the reality that producers aim to optimally adjust all factor inputs in response to changes in their relative prices. It is also consistent with reality to assume that factor inputs adjust to changing relative prices in an asymmetric fashion, rather
} 


\subsection{Decomposing Changes in Energy Demand}

Our primary focus in this study is to demonstrate producers' response to changing relative input prices. This response can be decomposed into substitution and output effects using the Slutsky equation. Following Chambers (1982) and Kim (1987) changes in input demand can be decomposed using the uncompensated Marshallian demand analysis where it is assumed that a firm maximizes output subject to a budget constraint on input costs:

$$
y\left(w^{\prime}, c\right)=\max _{\boldsymbol{x}}\left\{f\left(\boldsymbol{x}^{\prime}\right): \boldsymbol{w}^{\prime} \boldsymbol{x}=C\right\}
$$

The input demand functions are Marshallian ${ }^{11}$ in form:

$$
x_{k}=m_{k}\left(\boldsymbol{w}^{\prime}, C\right)
$$

where $x_{i}$ is the cost minimizing input demand, $\boldsymbol{w}$ is a vector of input prices and $C$ is the target level of input expenditure. Dual to this decision is the firm's cost function:

$$
c\left(\boldsymbol{w}^{\prime}, y\right)=\min _{\boldsymbol{x}^{\prime}}\left\{\boldsymbol{w}^{\prime} \boldsymbol{x}: y=f\left(\boldsymbol{x}^{\prime}\right)\right\}
$$

This has input demand functions that are Hicksian in form ${ }^{12}$ :

$$
x_{k}=h_{k}\left(\boldsymbol{w}^{\prime}, y\right)
$$

\footnotetext{
than in a symmetric manner as suggested by the AES. Further, unlike the AES, the MES allows for variable factor inputs within the production technology, rather than holding some factors fixed. For these reasons, we also explore the MES in this study.

${ }^{11}$ By the envelope theorem this satisfies Roy's identity: $x_{k}=m_{k}\left(\boldsymbol{w}^{\prime}, C\right)=-\frac{\partial y\left(\boldsymbol{w}^{\prime}, C\right)}{\partial w_{k}} / \frac{\partial y\left(\boldsymbol{w}^{\prime}, C\right)}{\partial C}$

${ }^{12}$ Again by the envelope theorem, these satisfy Shephard's lemma: $x_{k}=h_{k}\left(w^{\prime}, y\right)=\partial c\left(\boldsymbol{w}^{\prime}, y\right) / \partial w_{k}$
} 
Given the implicit relationship between the cost function and the indirect production function at the equilibrium point, the Marshallian input demand at cost $C$ is equal to Hicksian input demand at production $y$ :

$$
m_{k}\left(\boldsymbol{w}^{\prime}, C\right)=h_{k}\left(\boldsymbol{w}^{\prime}, \mathrm{y}\left(w^{\prime}, C\right)\right)
$$

Hicksian demand at production $y$ is equal to Marshallian demand at $\operatorname{cost} C$ :

$$
h_{k}\left(\boldsymbol{w}^{\prime}, y\right)=m_{k}\left(\boldsymbol{w}^{\prime}, c\left(\boldsymbol{w}^{\prime}, y\right)\right)
$$

These properties are brought together in the Slutsky equation to decompose the total effect of change in an input price into substitution and output effect. By taking the derivative of (14) w.r.t $\boldsymbol{w}_{i}$ using the composite rule we have:

$$
\frac{\partial h_{k}\left(\boldsymbol{w}^{\prime}, y\right)}{\partial w_{k}}=\frac{\partial m_{k}\left(\boldsymbol{w}^{\prime}, C\right)}{\partial c} \cdot \frac{\partial c\left(\boldsymbol{w}^{\prime}, y\right)}{\partial w_{k}}+\frac{\partial m_{k}\left(\boldsymbol{w}^{\prime}, C\right)}{\partial w_{k}}
$$

Using $x_{k}=h_{k}\left(w^{\prime}, y\right)=\partial c\left(\boldsymbol{w}^{\prime}, y\right) / \partial w_{k}$, we can re-arrange the equation to formulate a Slutsky relation:

$$
\frac{\partial m_{k}\left(\boldsymbol{w}^{\prime}, C\right)}{\partial w_{k}}=\frac{\partial h_{k}\left(\boldsymbol{w}^{\prime}, y\right)}{\partial w_{k}}-\frac{\partial m_{k}\left(\boldsymbol{w}^{\prime}, C\right)}{\partial c} m_{k}
$$

For the two-input case ( $k$ and $l)$, (16) can be written in a more parsimonious (uncompensated and compensated) elasticity form following Mundlak (1968):

$$
\eta_{k l}=\eta_{k l}^{c}-\eta_{k C} s_{l}
$$


From our estimated cost function, we can derive substitution and output effects as follows. The first term on the RHS of the equation $\eta_{k l}^{c}=\frac{\partial \ln \boldsymbol{h}_{k}\left(\boldsymbol{w}^{\prime}, y\right)}{\partial w_{l}}$ captures the substitution effect elasticity, which can be derived from the cross-partial elasticity of the estimated cost function as: $\eta_{k l}^{c}=\frac{\partial^{2} \ln c}{\partial \ln w_{k} \partial \ln w_{l}}=\gamma_{k l}$. The second RHS term is the output effect which has two components: $s_{l}$ is the cost/expenditure share of input $l$ which is computed as the ratio of input expenditure to total cost. The other component $\eta_{k C}=\frac{\partial \ln m_{k}(c, \boldsymbol{w})}{\partial \ln c}$ is the expenditure elasticity of input demand, which can be derived from the equilibrium relationship between the Marshallian and Hicksian demands in (13 and 14), so that $\eta_{k c}=\frac{\partial \ln x_{k}}{\partial \ln c}=\frac{\partial x_{k}}{\partial c} \frac{c}{x_{k}}=\left(\partial x_{k} / \partial y\right)(\partial y / \partial c)\left(c / x_{k}\right)$.

But then

$$
\left(\frac{\partial x_{k}}{\partial y}\right)\left(\frac{\partial y}{\partial c}\right)\left(\frac{c}{x_{k}}\right)=\left[\left(\frac{\partial \ln x_{k}}{\partial \ln y}\right)\left(\frac{x_{k}}{y}\right)\right]\left[\left(\frac{\partial \ln y}{\partial \ln c}\right)\left(\frac{y}{c}\right)\right]\left(\frac{c}{x_{k}}\right)
$$

Cancelling and using the inverse of the cost elasticity of output, $\left(\frac{\partial \ln C}{\partial \ln Y}\right)^{-1}$.

$$
\frac{\partial \ln x_{k}}{\partial \ln c}=\left(\frac{\partial \ln x_{k}}{\partial \ln y}\right)\left(\frac{\partial \ln y}{\partial \ln c}\right)=\delta_{k}\left(\varepsilon_{c y}\right)^{-1}
$$

Therefore we finally arrive at a computable format for the elasticity form of the cross effect Slutsky equation:

$$
\eta_{k l}=\gamma_{k l}-\left[\delta_{k}\left(\varepsilon_{c y}\right)^{-1}\right] s_{l}
$$




\section{Data}

Our estimations are based on the panel data of 33 sectors at two- and three-digit level using International Standard of Industrial Classification (ISIC) Rev. $2^{13}$ for Brazil, China, India, Indonesia and Russia over the period 1995-2009. The raw data series are mainly taken from the World Input-Output Database (WIOD) (Timmer et al., 2015). The measure of output is value added (y) which is expressed in millions of national currency. All monetary variables are measured in local currency at current prices. The measure of output is value added (y) expressed in millions of national currency, which we deflated using the price index of gross value added $(1995=100)$ also obtained from the WIOD. The constant value series are then converted to international prices using the purchasing power parity exchange rates from the Penn World Table (PWT7.1)

Similarly, for each of the four input sectors (capital, labour, energy and materials) we used producer price indices in each country in current prices from the World Input-Output Database; these are then deflated to constant $(1995=100)$ prices in each country by applying the implicit price deflator for that sector in each country from the same database. As in the case of output above, these constant price series are then converted to international prices using the purchasing power parity exchange rates from the Penn World Table (PWT7.1).

The input prices and total cost are computed as follows. The price of capital (pk) is computed as the ratio between capital compensation and Real fixed capital stock; the price of

\footnotetext{
${ }^{13}$ The sectors and their Industrial Classification are listed in the appendix.
} 
labour ( $\mathrm{pl}$ ) is derived as the ratio of labour compensation to the Number of persons engaged, while the price of energy (pe) is calculated as the ratio of intermediate energy input expenditure at current purchasers' prices to Gross energy use in TJ. The price of material (pm) is constructed as the ratio of value of intermediate material input expenditure at current purchasers' prices to intermediate material volume which is expressed as volume indices $(1995=100)$. The total cost is the sum of capital, labour, energy and material expenditure. Finally, the cost, output and input price data are in logarithms. For the estimations, we mean-adjusted all logged data for each variable, so that the first order coefficients in the model can be interpreted as elasticities at the sample mean. As shown in (5), the material price is the normalizing input.

\section{Estimation Results and Analysis}

This section presents the main results of the analysis undertaken in this study. It consists of three sub-sections. In the section 'Model results' we present the fitted cost functions and also comment on the curvature properties of the estimated models. In the section 'Substitution elasticities' we present the computed factor substitution between energy and the other factor inputs. In the final section 'Decomposition results' we discuss the substitution and output effects of change in energy demand across the sampled countries.

\subsection{Model results}

In Table 1, we present the parameter estimates of the fitted cost function with standard errors in parentheses. It can be seen from the results that the input price and output elasticities 
across the five models have the expected signs and they are all statistically significant at the $0.1 \%$ level. These parameters are all positive which indicates that the monotonicity of the cost function is satisfied at the sample mean. In particular, the elasticity of cost with respect to output gives an important measure of scale economies, such that an output elasticity smaller (larger) than one indicates scale economies (diseconomies) ${ }^{14}$. The output elasticities across all the models indicate strong economies of scale ranging from 1.8 in Brazil to 3.5 in China. The scale economies are sensible and consistent with the strong growth and output expansion across the BRIIC countries over the last two decades.

One intriguing result that emerges from this analysis is the role of economies of scale and factor accumulation as opposed to technical progress ${ }^{15}$ in giving rise to economic growth and energy use trend in these countries over the study period. This mirrors a debate that featured strongly in the research on growth performance during the years of the so-called Asian miracle and tiger economies. Liao et al (2007) identified two sides of the debate. Accumulationists believed that the increased use and accumulation of inputs (especially the investment) rather than the increases in productivity explains all growth; this was represented by Young (1992, 1994a, 1994b, 1995), Krugman (1994), Collins \& Bosworth (1996), Drysdale \& Huang (1997), Crafts (1999a, 1999b). Assimilationists argued that the answer to growth lies in the use of more efficient technology, represented by World Bank (1993), Sarel (1996, 1997), Nelson \& Pack (1999). Liao et al (2007) concluded that Krugman's (1994) hypothesis that the fast growth of East Asian economies had little to do with TFP growth was invalid, but could not dispute Young’s (1995) ‘s conclusion that these economies’ growth had been mainly input-driven.

\footnotetext{
${ }^{14}$ Of course, economies of scale is given by $1 / e y=\frac{1}{\partial \ln c(y, w) / \partial \ln y}$

${ }^{15}$ Technical progress is evaluated as the derivative of the cost (or input demand in the case of biased technical progress) function with respect to time, to derive panel-varying functional estimates.
} 
We find an almost identical issue arising in this sample of the BRIIC countries over the period 1995-2009. Our results show strong economies of scale but are unable to identify positive technical progress (compare the output elasticity of the estimated cost functions with the elasticity of cost with respect to time, which is consistently positive at the sample mean and over most of the individual panel sample points). The positive sign on the cost elasticity with respect to time implies that the cost function was shifting upwards over time. We investigated the robustness of this finding in two ways. In addition to the original iterative SURE estimation, we re-estimated all the models using one-way fixed and random effects panel methods. The importance of input accumulation over technical progress remained. Secondly, we re-estimated the models after imposing constant returns to scale on the technology; this should have the effect of eliminating any spurious scale effects and allowing positive technical progress to be discovered if it is present. The basic finding however is unchanged: technical progress is not estimated as being positive for these economies in this period. This means that the BRIIC economies have demonstrated the same experience as the Asian economies did a decade earlier, such that the principal engine of their growth has been factor accumulation rather than technical progress $^{16}$. It is in the context of this additional intriguing finding that we have been able to investigate output effect channel of changes in energy use.

\section{[Insert Table 1]}

In order to better understand the nature of the estimated technical progress above, we revisit the issue raised by Hunt (1986) about the importance of testing for non-neutrality (bias) in

\footnotetext{
${ }^{16}$ Interestingly, an edition (Oct. 11, 2014) of The Economist magazine highlighted this same issue that the Chinese economy's productivity growth between 1997 and 2012 had decelerated; and the TFP growth itself has been dominated by scale effects arising from huge accumulation of capital and capacity, rather than the efficiency within firm production technologies.
} 
the measure of technological progress. This is made more important by the nature of the Hicksian-neutral result above, which is more likely to be biased in the face of technological regress. We explore this by estimating restricted versions of (6) and (7) where we restrict $\xi_{j}$ to zero and then applied a likelihood ratio (LR) test statistic to test this restriction against the unrestricted model. The LR test statistic is given by $L R=2\left(\ln L_{U}-\ln L_{R}\right)$ where $L_{U}$ is the maximized value of the log likelihood of the unrestricted model and $L_{R}$ is the maximized $\log$ likelihood of the restricted model. The LR test statistic is asymptotically distributed as a chisquare distribution $\chi_{p}^{2}$, where p represents the number of restrictions (three in our case).

As shown in Table 2, the LR statistics show that the assumption or specification of neutral technical progress is clearly rejected across board with the LR statistics for all the models exceeding 7.81, the critical value for chi-square distribution with 3 degrees of freedom at the $5 \%$ level. With the exception of India, we generally found technical progress to be biased towards using energy across the sampled countries. This has important implications for issues such as rebound effects- in fact, rebound is a form of energy-using biased technical progress. These nonneutrality tests indicate that the assumption of Hicksian neutral technical progress should only be imposed when accepted by data, given that, in reality, technical progress may be biased towards using a particular input ${ }^{17}$.

\section{[Insert Table 2]}

\footnotetext{
${ }^{17}$ Kim (1987) shows that the assumption of Hicks-neutral technical progress is unrealistic in the face of firm's innovative activities. Fisher-Vanden and Jefferson (2008) found firm-level factor bias as an important channel of technical change in a large panel of Chinese industrial enterprises. Moreover, Felipe and McCombie (2001) show that accounting for the presence of biased technical change in a group of East Asian economies significantly impacted the estimates of total factor productivity (TFP) growth rates of these countries.
} 
Now turning to the economic properties of the estimated models, we briefly discuss the results on the monotonicity and concavity conditions of the fitted translog cost function which are presented in Table 3. We evaluate monotonicity and concavity ex post, both at the sample mean and at every point of the data sample ${ }^{18}$. As discussed above, the monotonicity condition was strongly satisfied at the sample mean, based on the statistically significant positive input price and output elasticities. Further, monotonicity is strongly satisfied outside the sample mean for all countries, with results indicating that for each of the five countries, a large proportion (at least $83 \%$ ) of the data points are monotonic. The results on monotonicity suggest that the estimated cost functions are non-decreasing in outputs and input prices.

For concavity, we checked the sign pattern of the principal minors of the Hessian. As shown in Table 3, concavity is confirmed at the sample mean across all fitted cost functions. In addition, we establish concavity at varying levels across the entire data points for the models, ranging from $29 \%$ concavity for Brazil to $97 \%$ in Indonesia ${ }^{19}$. The concavity condition (apart from Brazil) indicates that the cost function is concave in input prices i.e. firms are taking advantage of substitution opportunities to the extent that costs have grown slower than linearly, in response to changing relative factor prices. This appears to be supported by the significant scale economies observed across all the estimated cost functions. Unless this exercise is undertaken, it is impossible to determine the theoretical appropriateness of estimated production technologies.

\footnotetext{
${ }^{18}$ In other words, for monotonicity, we checked that the derivative of the cost function with respect to each input is positive; while the concavity test entails checking that the Hessian is negative semi-definite at the sample mean and at each point of the data sample.

${ }^{19}$ In terms of the concavity conditions, we checked for where the Hessian is negative semi-definite for each point of the dataset.
} 


\subsection{Substitution Elasticities}

[Insert Table 3]

We derive substitution elasticities following equations 7-8 using the cross-price parameters from the estimated translog model, as well as the factor shares ${ }^{20}$. Empirical elasticity results at the sample mean are presented in Table 4. In the interest of space, a more detailed presentation of the substitution elasticities across the different sectors in sampled countries is given in the appendix.

[Insert Table 4]

The standard errors of the estimated substitution elasticities are computed using the delta method (Binswanger, 1974; Koetse, et al., 2008). As shown in Table 4, our estimates at the sample mean generally indicate strong substitution possibilities between energy and other inputs for both the AES and the MES. However, we observe that the AES values are generally larger than the MES values in absolute terms. This might be due to the substantial asymmetries observed for the input combinations under the MES. This flexible substitution pattern under the MES, which is limited under the AES, possibly explains why the latter is likely to overstate elasticity of substitution (see Stiroh, 1999).

Briefly, our estimates indicate that energy is strongly substitutable for capital and labour, with estimated ES greater than 1 in most cases, and across both the AES and MES. The implication of this result is that firms/sectors across BRIIC countries strongly substituted energy for capital and labour with relative ease, in response to changing relative energy prices. We also

\footnotetext{
${ }^{20}$ The cross-price coefficients are taken from the fitted cost functions in Table 1 while the factor shares are computed as the ratio between expenditure on an input and total cost.
} 
computed sector-specific elasticities across the sampled countries to give a disaggregated view of energy substitutability. Generally, we also found strong substitutability between energy and the other two inputs ${ }^{21}$ as shown in the appendix. In particular, we found certain sectors with high substitution elasticities (in terms of the magnitude of the ES) such as Brazil (real estate, leather \& footwear and transport equipment); China (electrical \& optical equipment, leather \&footwear, rubber \& plastic, transport equipment, textiles, wood \& cork and paper \& pulp). Also for India the main sectors are education, food \& beverage, leather \& footwear, manufacturing and real estate; Indonesia (food \& beverage and machinery, NEC) and Russia (food \& beverage \& transport equipment).

\subsection{Decomposition results}

So far, we have only measured pure substitution elasticities without accounting for output effects. As shown by Chambers (1982), the implicit assumption in this case is that output is constant (i.e. these elasticties derived from cost functions restrict the producer to a given level of output). However, this assumption constitutes a serious limitation in the analysis of firm behavior because in reality, producers are likely to respond to changing relative prices, technological progress, external shocks and so forth, by adjusting output accordingly. Therefore, the output effect captures this adjustment process and gives a better and complete view of factor input adjustments within a production technology. For instance, previous oil price shocks have been shown to reduce output and productivity across firms and countries, to the extent that ignoring output effects in empirical studies of firm behavior results in the loss of valuable information (Kim, 1987; Frondel, 2011).

\footnotetext{
${ }^{21}$ We note, however, capital and energy are complements for some sectors in India and Russia (see appendix).
} 
Having estimated input demand function (7), we decomposed the change in energy demand into substitution and output effects following (20). We have only focused on the ownprice of effect of energy, which is relevant to our analysis. Table 5 presents the results of this decomposition.

\section{[Insert Table 5]}

Expectedly, the own substitution effects arising from increase in energy price are negative across all the countries, confirming the theoretical expectation that own-price substitution effects are negative (i.e. rising energy prices curbed energy demand). This also confirms that the Marshallian demands slope downwards. Further, this is also consistent with the widespread energy-non energy input substitutability across most sectors/countries since the negative own-price substitution effect indicates that higher energy prices caused productive units to substitute away towards other inputs and vice versa.

The output effects are positive across board, although they are strictly smaller than the substitution effects in absolute terms. As expected, this clearly shows that the substitution effects dominate the changes in energy demand arising from changing relative price of energy. Further, the positive sign on the output effects suggests that energy may not be a normal factor input across sampled economies because if firms are free to adjust output, we would expect that a rise in input price will raise total cost as well as marginal cost of production, making them produce less output overall. Nonetheless, in our case, it would appear that although rising energy prices restricted energy demand, the expected fall in output arising from higher total cost (negative output effect) has been countervailed by the significant economies of scale. Despite the opposing 
directions of both effects, the total effect is consistent with economic theory as higher energy prices led to a reduction in energy consumption largely through substitution effects.

\section{Concluding Remarks and Further Work}

Energy demand across fast emerging economies is rising rapidly, and this is expected to contribute significantly to future global energy consumption. A critical factor in the upward energy demand trend has been their rapid economic growth, driven largely by the evolution of strong industrial sectors. Therefore, a meaningful analysis of energy use across these economies requires a model that captures the nature and structure of the production technology across their productive sectors. In this paper, we have conducted an empirical analysis of the role of energy within the production technology of Brazil, Russia, India, Indonesia and China (BRIIC) for the period 1995-2009. In doing this, we focused on two major modelling issues. First, following duality theory we decomposed industrial energy demand into substitution and output effects. Second, we addressed a number of modelling issues which are crucial to understanding energy consumption of these economies in the context of a production technology. For instance, unlike previous studies, this paper investigated the economic properties and the nature of technical progress within the estimated cost functions.

Our results indicate strong substitutability between energy and other inputs. Further, the decomposition of changes in sectoral energy demand across BRIIC countries suggests that changes in energy demand are strongly dominated by substitution effects. In addition, our analysis revealed that economies of scale and factor accumulation, as opposed to technical progress have been the major drivers of firm performance in these countries over the period under consideration. This finding is consistent with the body of evidence on the nature of 
economic growth of emerging economies. The technical progress measure indicates that the cost function was shifting upwards during the period under consideration, and is also found to be largely biased (energy-using).

To a large extent, the estimated cost functions are found to honor the regularity conditions prescribed by microeconomic theory, with the models found to be strongly monotonic and largely concave. Unless these issues are explicitly investigated, it is impossible to determine the theoretical validity of any energy demand analysis conducted in the context of a production technology. The main idea behind this paper is particularly appealing because it is not limited to the analysis of firm behavior. Its application to consumer demand is straightforward and grounded in the same economic intuition. It is hoped that future research work will be conducted with focus on consumer demand. Of course the challenge is the lack of income and multi-product price data on developing countries.

\section{Acknowledgements}

We gratefully acknowledge the financial support provided by the School of Business and Economics, Loughborough University. The authors would also like to thank the editor, Prof Richard Tol and two anonymous referees for constructive comments which helped to improve the paper substantially. Of course, we are responsible for all errors and omissions. 


\section{References}

Adeyemi, O. I., Hunt, L. C., 2014. Accounting for asymmetric price responses and underlying energy demand trends in OECD industrial energy demand. Energy Economics, 45, 435-444.

Allen, R., 1938. Mathematical analysis for economists. MacMillan, London.

Berndt, E.R., Wood, D.O., 1975. Technology, prices, and the derived demand for energy. The Review of Economics and Statistics 57 (3), 259-268.

Binswanger, H.P., 1974. A cost function approach to the measurement of elasticities of factor demand and elasticities of substitution. American Journal of Agricultural Economics 56 (2), 377-386.

Blackorby, C., Russell, R., 1981. The morishima elasticity of substitution: symmetry, constancy, separability, and its relation to the Hicks and Allen elasticities. The Review of Economic Studies 48(1), 147-158.

Broadstock, D. C. 2010. Non-linear technological progress and the substitutability of energy for capital: An application using the translog cost function. Economics Bulletin, 30(1), 84-93.

Chambers, R. G., 1982. Duality, the output effect, and applied comparative statics. American Journal of Agricultural Economics 64 (1), 152-156.

Christensen, L., Jorgenson, D., Lau, L., 1973. Transcendental logarithmic production frontiers. The Review of Economics and Statistics 55(1), 28-45. 
Collins, S., Bosworth, B., 1996. Economic growth in East Asia: Accumulation versus assimilation. Brookings Papers in Economic Activity 2, 135-203.

Costanza, R., 1980. Embodied energy and economic valuation. Science 210 (4475), 1219-1224.

Crafts, N., 1999a. East Asian growth before and after the Crisis. IMF Staff Papers 46(2), International Monetary Fund

Crafts, N., 1999b. Economic growth in the twentieth century. Oxford Review of Economic Policy, 15(4) 18-34.

Dimitropoulos, J., Hunt, L.C., Judge, G., 2005. Estimating underlying energy demand trends using UK annual data. Applied Economics Letters 12 (4), 239-244.

Drysdale, P., Huang, Y., 1997. Technological catch-up and economic growth in East Asia and the Pacific. The Economic Record 73, 201-211.

Felipe, J., McCombie, J.S.L., 2001. Biased technical change, growth accounting, and the conundrum of the East Asian miracle. Journal of Comparative Economics 29, 542-565.

Fisher-Vanden, K., Jefferson, G.H., 2008. Technology diversity and development: evidence from China’s industrial enterprises. Journal of Comparative Economics 36, 658-672.

Frondel, M., 2011. Modelling energy and non-energy substitution: A brief survey of elasticities. Energy Policy 39 (8), 4601-4604.

Goel, R.K., Koehonen, I. 2012. Economic growth in BRIC countries and comparisons with rest of the world, Economia Internazionale / International Economics, Camera di Commercio di Genova 65(3), 447-471.

Hunt, L.C., 1984. Energy and capital: substitutes or complements? Some results for the UK industrial sector. Applied Economics 16 (5), 783-789.

Hunt. L.C., 1986. Energy and capital: substitutes or complements? A note on the importance of testing for non-neutral technical progress. Applied Economics, 18 (7), 729-735.

International Energy Agency, 2014: World Energy Balances 2014 edition. Mimas, University of Manchester.

Kim, H.Y., 1987. Decomposition analysis of derived demand for factor inputs with biased technical change and output adjustment. Bulletin of Economic Research 39 (2), 179-183.

Koetse, M., de Groot, H., Florax, R., 2008. Capital-energy substitution and shifts in factor demand: A meta-analysis. Energy Economics 30 (5), 2236-2251. 
Krugman, P., 1994. The myth of Asia’s miracle. Foreign affairs 73(6), 62-78.

Liao, H., Holmes, M., Weyman-Jones, T., Llewellyn, D., 2007. Productivity growth of East Asia economies' manufacturing: A decomposition analysis. Journal of Development Studies 43 (4), 649-674.

Medlock III, K.B., Soligo, R., 2001. Economic development and end-use energy demand. Energy Journal 22 (2), 77-105.

Morishima, M., 1967. A few suggestions on the theory of elasticity. Economic Review 16, 144150.

Mundlak, Y., 1968. Elasticities of substitution and the theory of derived demand. The Review of Economic Studies 35 (2), 225-236.

Nelson, R. P., Pack, H., 1999. The Asian miracle and modern growth theory. Economic Journal 109(457), 416-436.

Roy, J., Sanstad, A. H., Sathaye, J. A., Khaddaria, R. (2006). Substitution and price elasticity estimates using inter-country pooled data in a translog cost model. Energy economics, 28(5), 706-719.

Sarel, M., 1996. Growth in East Asia: What we can and what we cannot infer. Economic Issues No.1, IMF, Sept. 1996.

Sarel, M., 1997. Growth and productivity in ASEAN countries. IMF Working Paper, WP/97/97, International Monetary Fund.

Saunders, H.D., 2008. Fuel conserving (and using) production functions. Energy Economics 30 (5), 2184-2235.

Saunders, H.D., 2013. Is what we think of as “rebound” really just income effects in disguise? Energy Policy 57, 308-317.

Stern, D.I., 2011. Elasticities of substitution and complementarity. Journal of Productivity Analysis 36 (1), 79-89.

Stiroh, K.J., 1999. Measuring input substitution in thrifts: Morishima, Allen-Uzawa, and crossprice elasticities. Journal of Economics and Business 51 (2), 145-157.

The Economist, 2014. Unproductive Production, (print edition) October 112014.

Thompson. H, (2006), The applied theory of energy substitution in production, Energy Economics, 28 (4), 410-425. 
Timmer, M. P., Dietzenbacher, E., Los, B., Stehrer, R., \& Vries, G. J. (2015). An Illustrated User Guide to the World Input-Output Database: the Case of Global Automotive Production. Review of International Economics. (DOI: 10.1111/roie.12178)

Uzawa, H., 1962. Production functions with constant elasticities of substitution. The Review of Economic Studies 29, 291-299.

World Bank, 1993. The East Asian miracle: Economic growth and public policy. New York: Oxford University Press.

Young, A., 1992. A tale of two cities: Factor accumulation and technical change in Hong Kong and Singapore in Oliver J. Blanchard \& Stanley Fisher (eds) NBER Macroeconomics Annual 1992, Cambridge MA, MIT Press, 13-54.

Young, A., 1994a. Accumulation , exports and growth in the high performing Asian economies. A comment. Carnegie-Rochester Conference Series on Public Policy 40, 237-250.

Young, A., 1994b. Lessons from the East Asian NICs: A contrarian view. European Economic Review XXXVIII, 964-973.

Young, A., 1995. The tyranny of numbers: Confronting the statistical realities of the East Asian growth experience. Quarterly Journal of Economics CVV, 641-680.

\section{Appendix}

\section{Test of the monotonicity and concavity condition}

For a cost function $c(y, w)$ to be well-behaved, microeconomic theory prescribes that it exhibits monotonicity and curvature properties.

\section{Monotonicity}

The monotonicity conditions are given as:

(i) non-decreasing in outputs, $y, \partial \ln c(y, w) / \partial \ln y_{r} \equiv e y_{r} \geq 0, j=1, \ldots, J$;

(ii) non-decreasing in input prices, $w, \partial \ln c(y, w) / \partial \ln w_{k} \equiv e w_{k} \geq 0, k=1, \ldots, ; K$ 
These conditions are checked by obtaining the output and input price elasticities, $e y_{r}=$ $\partial \ln c(y, w) / \partial \ln y_{r}$ and $e w_{k}=\partial \ln c(y, w) / \partial \ln w_{k}$ both at the sample mean and at each data point.

\section{Concavity}

The concavity condition requires that the cost function is a concave and continuous function in inputs prices $w$.This condition is satisfied when the Hessian of the cost function with respect to input prices $w$ is negative semi-definite. The negative semi-definiteness of the Hessian can be confirmed from the alternating sign pattern of its principal minors. The necessary and sufficient condition for concavity is that all the odd-numbered principal minors of the Hessian must be non-positive and all the even-numbered principal minors must be non-negative. The Hessian of the cost function can be written as:

$$
H(w)=\boldsymbol{\delta}-\hat{\boldsymbol{s}}+\boldsymbol{s} \boldsymbol{s}^{T}
$$

where $\boldsymbol{\delta}$ is the matrix of second-order coefficients on the input prices. By Shepherd's lemma, the share equations can be expressed as $s_{k}=\partial \ln c(y, w) / \partial \ln w_{k}=e w_{k}$ in which case $\boldsymbol{s}$ is a column matrix of share equations, so that $\boldsymbol{s}^{\prime}=\left[s_{1}, \ldots, s_{m}\right]^{\prime}$ and $\hat{\boldsymbol{s}}$ is the diagonal matrix with share $s_{m}$ on the main diagonal. 


\section{List of NACE rev 1 (ISIC rev 2) Sectors}

\begin{tabular}{|c|c|c|}
\hline Code & NACE Description & Sector \\
\hline 1 & AtB & Agriculture, Hunting, Forestry and Fishing \\
\hline 2 & $\mathrm{C}$ & Mining and Quarrying \\
\hline 3 & $15 t 16$ & Food, Beverages and Tobacco \\
\hline 4 & $17 \mathrm{t} 18$ & Textiles and Textile Products \\
\hline 5 & 19 & Leather, Leather and Footwear \\
\hline 6 & 20 & Wood and Products of Wood and Cork \\
\hline 7 & $21 \mathrm{t} 22$ & Pulp, Paper, Paper , Printing and Publishing \\
\hline 8 & 23 & Coke, Refined Petroleum and Nuclear Fuel \\
\hline 9 & 24 & Chemicals and Chemical Products \\
\hline 10 & 25 & Rubber and Plastics \\
\hline 11 & 26 & Other Non-Metallic Mineral \\
\hline 12 & $27 \mathrm{t} 28$ & Basic Metals and Fabricated Metal \\
\hline 13 & 29 & Machinery, Nec \\
\hline 14 & $30 \mathrm{t} 33$ & Electrical and Optical Equipment \\
\hline 15 & $34 \mathrm{t} 35$ & Transport Equipment \\
\hline 16 & $36 \mathrm{t} 37$ & Manufacturing, Nec; Recycling \\
\hline 17 & $\mathrm{E}$ & Electricity, Gas and Water Supply \\
\hline 18 & $\mathrm{~F}$ & Construction \\
\hline 20 & 51 & Wholesale Trade and Commission Trade, Except of Motor Vehicles \\
\hline 21 & 52 & Retail Trade, Except of Motor Vehicles ; Repair of Household Goods \\
\hline 22 & $\mathrm{H}$ & Hotels and Restaurants \\
\hline 23 & 60 & Inland Transport \\
\hline 24 & 61 & Water Transport \\
\hline
\end{tabular}




\begin{tabular}{|l|c|l|}
25 & 62 & Air Transport \\
26 & 63 & Other Supporting and Auxiliary Transport Activities; Activities of Travel Agencies \\
27 & 64 & Post and Telecommunications \\
28 & $\mathrm{~J}$ & Financial Intermediation \\
29 & 70 & Real Estate Activities \\
30 & $71 \mathrm{t} 74$ & Renting of M\&Eq and Other Business Activities \\
31 & $\mathrm{M}$ & Education \\
32 & $\mathrm{~N}$ & Health and Social Work \\
33 & $\mathrm{O}$ & Other Community, Social and Personal Services \\
\hline
\end{tabular}

